\title{
Differential Impact of Hyperglycemia in Critically Ill Patients: Significance in Acute Myocardial Infarction but Not in Sepsis?
}

\author{
Bernhard Wernly ${ }^{1}$, Michael Lichtenauer ${ }^{1}$, Marcus Franz ${ }^{2}$, Bjoern Kabisch ${ }^{2}$, Johanna Muessig ${ }^{3}$, \\ Maryna Masyuk ${ }^{3}$, Malte Kelm ${ }^{3}$, Uta C. Hoppe ${ }^{1}$ and Christian Jung ${ }^{3, *}$ \\ 1 Clinic of Internal Medicine II, Department of Cardiology, Paracelsus Medical University of Salzburg, \\ Salzburg A-5020, Austria; b.wernly@salk.at (B.W.); m.lichtenauer@salk.at (M.L.); u.hoppe@salk.at (U.C.H.) \\ 2 Clinic of Internal Medicine I, Department of Cardiology, Jena University Hospital, Thuringia 07743, \\ Germany; marcus.franz@med.uni-jena.de (M.F.); bjoern.kabisch@med.uni-jena.de (B.K.) \\ 3 Division of Cardiology, Pulmonology, and Vascular Medicine, Medical Faculty, University Duesseldorf, \\ Düsseldorf 40225, Germany; johanna.muessig@med.uni-duesseldorf.de (J.M.); \\ maryna.masyuk@med.uni-duesseldorf.de (M.M.); malte.kelm@med.uni-duesseldorf.de (M.K.) \\ * Correspondence: christian.jung@med.uni-duesseldorf.de; Tel.: +49-211-811-8567; Fax: +49-211-811-8812
}

Academic Editor: Lu Cai

Received: 5 August 2016; Accepted: 12 September 2016; Published: 21 September 2016

\begin{abstract}
Hyperglycemia is a common condition in critically ill patients admitted to an intensive care unit (ICU). These patients represent an inhomogeneous collective and hyperglycemia might need different evaluation depending on the underlying disorder. To elucidate this, we investigated and compared associations of severe hyperglycemia ( $>200 \mathrm{mg} / \mathrm{dL}$ ) and mortality in patients admitted to an ICU for acute myocardial infarction (AMI) or sepsis as the two most frequent admission diagnoses. From 2006 to 2009, 2551 patients 69 (58-77) years; 1544 male; 337 patients suffering from type 2 diabetes (T2DM)) who were admitted because of either AMI or sepsis to an ICU in a tertiary care hospital were investigated retrospectively. Follow-up of patients was performed between May 2013 and November 2013. In a Cox regression analysis, maximum glucose concentration at the day of admission was associated with mortality in the overall cohort (HR $=1.006,95 \%$ CI: $1.004-1.009$; $p<0.001)$ and in patients suffering from myocardial infarction (HR $=1.101,95 \% \mathrm{CI}: 1.075-1.127$; $p<0.001$ ) but only in trend in patients admitted to an ICU for sepsis (HR $=1.030,95 \%$ CI: $0.998-1.062$; $p=0.07)$. Severe hyperglycemia was associated with adverse intra-ICU mortality in the overall cohort ( $23 \%$ vs. $13 \% ; p<0.001)$ and patients admitted for AMI $(15 \%$ vs. $5 \% ; p<0.001)$ but not for septic patients ( $39 \%$ vs. $40 \% ; p=0.48)$. A medical history of type 2 diabetes $(n=337 ; 13 \%)$ was not associated with increased intra-ICU mortality ( $15 \%$ vs. $15 \% ; p=0.93)$ but in patients with severe hyperglycemia and/or a known medical history of type 2 diabetes considered in combination, an increased mortality in AMI patients (intra-ICU $5 \%$ vs. $13 \% ; p<0.001$ ) but not in septic patients (intra-ICU $38 \%$ vs. $41 \%$; $p=0.53$ ) could be evidenced. The presence of hyperglycemia in critically ill patients has differential impact within the different etiological groups. Hyperglycemia in AMI patients might identify a sicker patient collective suffering from pre-diabetes or undiagnosed diabetes with its' known adverse consequences, especially in the long-term. Hyperglycemia in sepsis might be considered as adaptive survival mechanism to hypo-perfusion and consecutive lack of glucose in peripheral cells. AMI patients with hyperglycemic derailment during an ICU-stay should be closely followed-up and extensively screened for diabetes to improve patients' outcome.
\end{abstract}

Keywords: hyperglycemia; sepsis; myocardial infarction; critically ill; stress hyperglycemia; diabetes; prediabetes 


\section{Introduction}

Hyperglycemia is a common condition in critically ill patients. Transient hyperglycemia in this context is usually referred to as "stress hyperglycemia" [1-3]: In contrast to hyperglycemia due to type 2 diabetes mellitus, stress hyperglycemia is primarily caused by hepatic gluconeogenesis and glycogenolysis [4]. Patients admitted to an intensive care unit (ICU) represent an inhomogeneous collective and hyperglycemia might need a differential evaluation depending on the underlying disorder.

Hyperglycemic derailment is known to be associated with adverse outcome and increased mortality in patients suffering from an acute myocardial infarction (AMI) [5]. In these patients there is an ongoing debate whether increased glucose concentration constitutes an independent risk factor or depicts only a severity parameter of illness in certain circumstances. Of note, the association between stress hyperglycemia and mortality in AMI patients is at least more pronounced in non-diabetic patients, and it was speculated that patients with pre-existing diabetes mellitus undergo cellular adaptation to hyperglycemia as reactive oxygen species production by the mitochondria is reduced [6,7].

In septic patients severe hyperglycemia (blood glucose $>200 \mathrm{mg} / \mathrm{dL}$ ) but not mild hyperglycemia (141-199 mg/dL) was recently reported to be associated with increased mortality [8]. Up to a certain degree, stress hyperglycemia is thought to be adaptive to hemodynamic changes in patients suffering from sepsis [9]: Sufficient glucose supply is essential for all cells. As sepsis leads to hypo-perfusion and glucose uptake depends on a concentration gradient, an increase in blood glucose levels is a physiologic and necessary response mechanism to hypo-perfusion [10]. Whereas in the early 2000s tight glucose control in septic patients was thought to be beneficial, it could be shown in large, prospective trials that intensive glucose control is even detrimental for these patients [11-13]. Therefore, in septic patients, stress hyperglycemia is considered a beneficial response of the organism and only liberal management of high glucose, avoiding glucose concentrations leading to fluid shifts by serum osmolality changes, is recommended [14]. It is well known that patients suffering from diabetes are at increased risk for infection and sepsis due to humoral defects and impaired host response [15-17]. Even though, and in contrast to AMI patients, septic patients with known diabetes mellitus do not reveal increased mortality as reported by van Vught et al. and Esper et al. [8,18].

Both, septic and AMI patients are frequently admitted to ICUs, but a detailed assessment of these collectives is needed. We therefore compared associations of severe hyperglycemia and mortality in ICU patients suffering from either AMI or sepsis with and without pre-diagnosed diabetes mellitus.

\section{Results}

In total, 2551 patients were investigated. Among these, 572 were admitted to the ICU due to sepsis and 1979 patients because of an AMI. Mean follow-up time was $2135 \pm 45$ days. Baseline characteristics are shown in Table 1. Patients admitted for sepsis were of similar age (68 (58-77) vs. 69 (59-77) years, $p=0.18$ ) but were clinically sicker as mirrored by both, higher SAPS2 (54 \pm 20 vs. $33 \pm 16 ; p<0.001)$ and APACHE ( $26 \pm 8$ vs. $16 \pm 8 ; p<0.001)$ scores compared to patients admitted for AMI. Further, heart rate was higher in septic patients (118 \pm 18 vs. $91 \pm 20 \mathrm{bpm}$ (beats per minute); $p<0.001)$ and they evidenced more pronounced laboratory organ failure, higher white blood cell count $(16.5 \pm 14.1$ vs. $11.2 \pm 4.7 ; p<0.001)$ and lactate concentration $(4.4 \pm 4.9$ vs. $2.1 \pm 3.3 \mathrm{mmol} / \mathrm{L}$; $p<0.001$ ) on the admission day as shown in Table 1. 
Table 1. Baseline characteristics of the overall cohort, patients admitted for sepsis and patients admitted for AMI.

\begin{tabular}{ccccc}
\hline Parameter & Overall Cohort & Admitted for Sepsis & Admitted for MI & $p$-Value \\
\hline age & $69(58-77)$ & $68(67-76)$ & $69(59-77)$ & 0.18 \\
male & $61 \%$ & $60 \%$ & $62 \%$ & 0.42 \\
lactate $(\mathrm{mmol} / \mathrm{L})$ & $2.69 \pm 3.93$ & $4.35 \pm 4.94$ & $2.10 \pm 3.31$ & $<0.001$ \\
glucose $(\mathrm{mg} / \mathrm{dL})$ & $180 \pm 72$ & $195 \pm 67$ & $175 \pm 73$ & $<0.001$ \\
leucocytes $(\mathrm{G} / \mathrm{L})$ & $12.43 \pm 8.19$ & $16.54 \pm 14.05$ & $11.23 \pm 4.74$ & $<0.001$ \\
$($ lowest) $\mathrm{pO}(\mathrm{kPa})$ & $9.12 \pm 2.12$ & $5.35 \pm 1.00$ & $5.63 \pm 1.92$ & 0.005 \\
pCO2 $(\mathrm{kPa})$ & $6.12 \pm 1.85$ & $6.76 \pm 2.33$ & $5.66 \pm 1.38$ & $<0.001$ \\
heart rate $(\mathrm{bpm})$ & $97 \pm 23$ & $118 \pm 23$ & $91 \pm 20$ & $<0.001$ \\
sodium $(\mathrm{mmol} / \mathrm{L})$ & $140.02 \pm 4.63$ & $141.72 \pm 7.14$ & $139.65 \pm 3.76$ & $<0.001$ \\
potassium $(\mathrm{mmol} / \mathrm{L})$ & $4.20 \pm 0.54$ & $4.27 \pm 0.67$ & $4.10 \pm 0.50$ & $<0.001$ \\
type 2 diabetes & $13 \%$ & $13 \%$ & $13 \%$ & - \\
creatinine $(\mu \mathrm{mol} / \mathrm{L})$ & $95(78-95)$ & $180(112-297)$ & $89(76-116)$ & $<0.001$ \\
ALAT $\left(\mu \mathrm{mol} /\left(\mathrm{l}^{*} \mathrm{~s}\right)\right)$ & $0.7(0.4-1.3)$ & $0.7(0.3-1.4)$ & $0.7(0.5-1.2)$ & 0.007 \\
ASAT $\left(\mu \mathrm{mol} /\left(\mathrm{l}^{*} \mathrm{~s}\right)\right)$ & $1.6(0.7-4.2)$ & $1.0(0.5-2.6)$ & $2.1(0.8-4.7)$ & $<0.001$ \\
APACHE score & $20 \pm 10$ & $26 \pm 8$ & $16 \pm 8$ & $<0.001$ \\
SAPS2 score & $40 \pm 20$ & $54 \pm 20$ & $33 \pm 16$ & $<0.001$ \\
\hline
\end{tabular}

As continuous variable, maximum glucose concentration on the day of admission was associated in a Cox regression analysis with mortality in the overall cohort (HR $=1.006,95 \%$ CI: 1.004-1.009; $p<0.001)$ and in patients suffering from AMI (HR $=1.101,95 \%$ CI: $1.075-1.127 ; p<0.001)$ but only in trend in patients admitted to an ICU for sepsis (HR 1.030, 95\% CI: 0.998-1.062; $p=0.07$ ) (Table 2).

Table 2. In a Cox regression analysis, maximum glucose concentration on the day of admission was associated with mortality in the overall cohort and those patients admitted for AMI.

\begin{tabular}{cccc}
\hline Group & HR & $\mathbf{9 5 \%}$ CI & $p$-Value \\
\hline overall cohort & 1.006 & $1.004-1.127$ & $<0.001$ \\
admitted for sepsis & 1.03 & $0.998-1.062$ & 0.07 \\
admitted for AMI & 1.101 & $1.075-1.127$ & $<0.001$ \\
\hline
\end{tabular}

To further analyze effects of severe hyperglycemia (i.e., a glucose concentration above $200 \mathrm{mg} / \mathrm{dL}$ ) we split our cohort in two groups based on this cut-off. In the overall cohort, patients with severe hyperglycemia were older (71 (63-78) vs. 69 (57-77) years; $p<0.001$ ), more obese (BMI $28 \pm 5$ vs. $27 \pm 4$; $p<0.01$ ) and sicker (APACHE2 score $24 \pm 10$ vs. $19 \pm 9 ; p<0.01$; SAPS2 score $47 \pm 20$ vs. $39 \pm 20$; $p<0.01$ ). Patients suffering from severe hyperglycemia evidenced higher lactate concentrations $(4.1 \pm 5.8$ vs. $2.4 \pm 3.1 ; p<0.001)$, higher heart rate $(107 \pm 24$ vs. $98 \pm 23$ bpm; $p<0.001)$ and more pronounced laboratory multi-organ failure as shown in Table 3. In our overall population, severe hyperglycemia ( $>200 \mathrm{mg} / \mathrm{dL}$ ) was associated with increased mortality both intra-ICU (23\% vs. 13\%; $p<0.001)$ and long-term $(\mathrm{HR}=1.74,95 \%$ CI: 1.44-2.09; $p<0.001)$ (Table 4 and Figure 1$)$. 
Table 3. In the overall cohort, patients suffering from severe hyperglycemia ( $>200 \mathrm{mg} / \mathrm{dL}$ ) were sicker (SAPS2 score $47 \pm 20$ vs. $39 \pm 20 ; p<0.001)$ and older $(71(62-78)$ vs. 68 (57-77) years; $p<0.001)$.

\begin{tabular}{cccc}
\hline Parameter & $<\mathbf{2 0 0} \mathbf{~ m g / d L}$ & $>\mathbf{2 0 0} \mathbf{~ m g} / \mathbf{d L}$ & $p$-Value \\
\hline age & $68(57-77)$ & $71(63-78)$ & $<0.001$ \\
male & $60 \%$ & $64 \%$ & 0.04 \\
lactate $(\mathrm{mmol} / \mathrm{L})$ & $2.42 \pm 3.12$ & $4.05 \pm 5.81$ & $<0.001$ \\
glucose $(\mathrm{mg} / \mathrm{dL})$ & $143 \pm 30$ & $267 \pm 66$ & $<0.001$ \\
leucocytes $(\mathrm{G} / \mathrm{L})$ & $12.07 \pm 8.49$ & $15.10 \pm 9.51$ & $<0.001$ \\
$($ lowest $) \mathrm{pO}(\mathrm{kPa})$ & $5.45 \pm 1.44$ & $5.26 \pm 1.31$ & 0.09 \\
$\mathrm{pCO} 2(\mathrm{kPa})$ & $5.88 \pm 1.66$ & $6.40 \pm 2.16$ & $<0.001$ \\
heart rate $(\mathrm{bpm})$ & $98 \pm 23$ & $107 \pm 24$ & $<0.001$ \\
sodium $(\mathrm{mmol} / \mathrm{L})$ & $139.90 \pm 4.41$ & $140.67 \pm 6.28$ & 0.03 \\
potassium $(\mathrm{mmol} / \mathrm{L})$ & $4.12 \pm 0.54$ & $4.20 \pm 0.64$ & 0.07 \\
type 2 diabetes & $10 \%$ & $25 \%$ & $<0.001$ \\
creatinine $(\mu \mathrm{mol} / \mathrm{L})$ & $95(77-152)$ & $120(89-199)$ & $<0.001$ \\
ALAT $\left(\mu \mathrm{mol} /\left(\mathrm{l}^{*} \mathrm{~s}\right)\right)$ & $0.7(0.4-1.3)$ & $0.8(0.5-1.5)$ & $<0.001$ \\
ASAT $\left(\mu \mathrm{mol} /\left(\mathrm{l}^{*} \mathrm{~s}\right)\right)$ & $1.4(0.6-4.1)$ & $1.8(0.7-5.1)$ & $<0.001$ \\
APACHE score & $19 \pm 9$ & $24 \pm 10$ & $<0.001$ \\
SAPS2 score & $39 \pm 20$ & $47 \pm 20$ & $<0.001$ \\
BMI $\left(\mathrm{kg} / \mathrm{m}^{2}\right)$ & $27 \pm 4$ & $28 \pm 5$ & $<0.001$ \\
\hline
\end{tabular}

Table 4. Severe hyperglycemia was associated with adverse short-term outcome in the overall cohort $(23 \%$ vs. $13 \% ; p<0.001)$ and patients admitted for AMI $(15 \%$ vs. $5 \%$; $p<0.001)$ but not for septic patients $(39 \%$ vs. $40 \%$; $p=0.48)$.

\begin{tabular}{cccccc}
\hline Group & HR & $\mathbf{9 5 \%} \mathbf{C I}$ & $\boldsymbol{p}$-Value & $\begin{array}{c}\text { Glucose } \\
<\mathbf{2 0 0} \mathbf{~} \mathbf{g} / \mathbf{d L}\end{array}$ & $\begin{array}{c}\text { Glucose } \\
\mathbf{2 0 0} \mathbf{~ m g} / \mathbf{d L}\end{array}$ \\
\hline overall cohort & 1.88 & $(1.46-2.43)$ & $<0.001$ & $13 \%$ & $23 \%$ \\
admitted for sepsis & 1.02 & $(0.71-1.47)$ & 0.48 & $39 \%$ & $40 \%$ \\
admitted for MI & 3.02 & $(2.01-4.54)$ & $<0.001$ & $5 \%$ & $15 \%$ \\
\hline
\end{tabular}

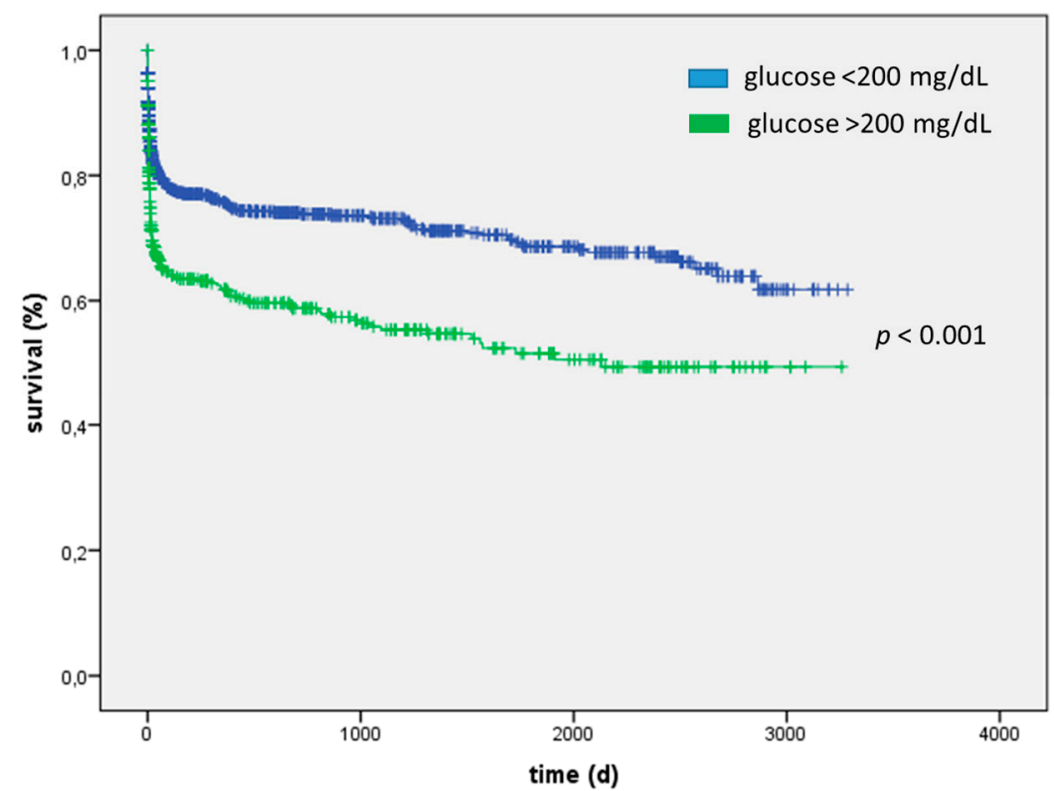

Figure 1. In the overall population severe hyperglycemia ( $>200 \mathrm{mg} / \mathrm{dL}$ ) was associated with increased mortality in the long-term (HR 1.74, 95\% CI: 1.44-2.09; $p<0.001)$.

For patients admitted for sepsis, severe hyperglycemia was not associated with increased mortality, neither short-term $(40 \%$ vs. $39 \% ; p=0.5)$ nor long-term $(\mathrm{HR}=1.13,95 \% \mathrm{CI}: 0.89-1.44 ; p=0.32)$ 
(Table 4 and Figure 2). AUC for blood glucose concentration was low (AUC 0.52, 95\% CI: 0.49-0.56). Interestingly, in sepsis, severe hyperglycemic patients were of equal age compared with those without severe hyperglycemia (68 (59-77) vs. $68(55-76)$ years; $p=0.21)$ and whereas APACHE2 score was higher ( $28 \pm 8$ vs. $26 \pm 8 ; p=0.02)$ SAPS2 scores ( $55 \pm 20$ vs. $53 \pm 20 ; p=0.25)$ did not differ between the groups indicating a clinically similarly sick collective. Further biomarkers of renal (creatinine $184(114-317)$ vs. $180(112-292) \mu \mathrm{mol} / \mathrm{L} ; p=0.46)$ and liver failure (ALAT 0.7 (0.4-1.2) vs. 0.7 (0.3-1.4) $\mu \mathrm{mol} /\left(\mathrm{l}^{*} \mathrm{~s}\right), p=0.69$; ASAT $1.1(0.5-2.9)$ vs. $\left.1.0(0.4-2.5) \mu \mathrm{mol} /\left(\mathrm{l}^{*} \mathrm{~s}\right), p=0.34\right)$ and blood lactate concentration $(4.8 \pm 5.3$ vs. $4.1 \pm 4.8 \mathrm{mmol} / \mathrm{L} ; p=0.17)$ and heart rate $(119 \pm 23$ vs. $118 \pm 22 \mathrm{bpm}$; $p=0.65$ ) were similar (Table 5).

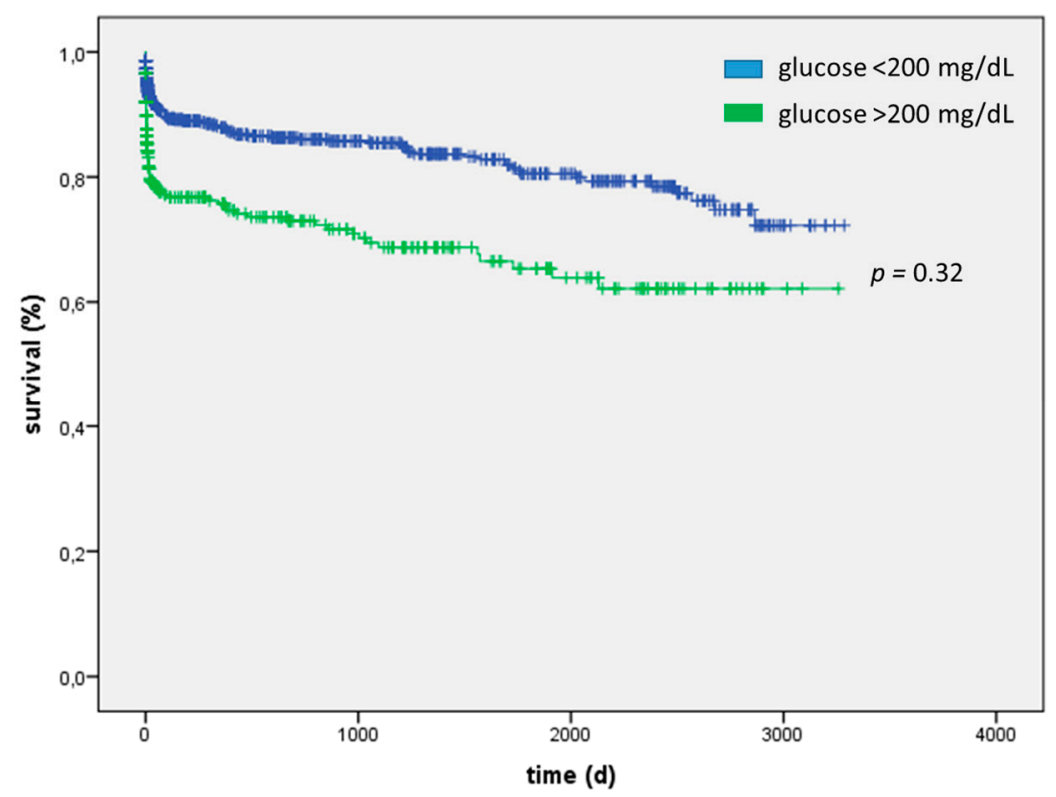

Figure 2. Patients admitted for sepsis and suffering from severe hyperglycemia did not evidence increased mortality in the long-term (HR 1.13, 95\% CI: 0.89-1.44; $p=0.32$ ).

Table 5. Patients admitted for sepsis and suffering from severe hyperglycemia ( $>200 \mathrm{mg} / \mathrm{dL}$ ) were of equal age (68 (55-76) vs. 68 (59-77) years; $p=0.21$ ) and SAPS2 scores did not differ (52 \pm 20 vs. $55 \pm 20$; $p=0.25)$.

\begin{tabular}{cccc}
\hline Parameter & $<\mathbf{2 0 0} \mathbf{~ m g} / \mathbf{d L}$ & $>\mathbf{2 0 0} \mathbf{~ m g} / \mathbf{d L}$ & $p$-Value \\
\hline age & $68(55-76)$ & $68(59-77)$ & 0.21 \\
male & $61 \%$ & $62 \%$ & 0.85 \\
lactate $(\mathrm{mmol} / \mathrm{L})$ & $4.14 \pm 4.76$ & $4.75 \pm 5.25$ & 0.17 \\
glucose $(\mathrm{mg} / \mathrm{dL})$ & $156 \pm 29$ & $260 \pm 62$ & $<0.001$ \\
leucocytes $(\mathrm{G} / \mathrm{L})$ & $15.22 \pm 13.99$ & $18.73 \pm 13.95$ & 0.006 \\
(lowest) $\mathrm{pO} 2(\mathrm{kPa})$ & $5.32 \pm 0.95$ & $5.39 \pm 0.99$ & 0.55 \\
pCO2 $(\mathrm{kPa})$ & $6.60 \pm 2.20$ & $7.02 \pm 2.51$ & 0.04 \\
heart rate $(\mathrm{bpm})$ & $118 \pm 22$ & $119 \pm 23$ & 0.65 \\
sodium $(\mathrm{mmol} / \mathrm{L})$ & $141.48 \pm 6.96$ & $142.14 \pm 7.44$ & 0.43 \\
potassium $(\mathrm{mmol} / \mathrm{L})$ & $4.27 \pm 0.65$ & $4.28 \pm 0.70$ & 0.92 \\
type 2 diabetes & $12 \%$ & $17 \%$ & 0.07 \\
creatinine $(\mu \mathrm{mol} / \mathrm{L})$ & $180(112-292)$ & $184(114-317)$ & 0.46 \\
ALAT $\left(\mu \mathrm{mol} /\left(\mathrm{l}^{*} \mathrm{~s}\right)\right)$ & $0.7(0.3-1.4)$ & $0.7(0.4-1.2)$ & 0.69 \\
ASAT $\left(\mu \mathrm{mol} /\left(\mathrm{l}^{*} \mathrm{~s}\right)\right)$ & $1.0(0.4-2.5)$ & $1.1(0.5-2.9)$ & 0.34 \\
APACHE score & $26 \pm 8$ & $28 \pm 8$ & 0.02 \\
SAPS2 score & $53 \pm 20$ & $55 \pm 20$ & 0.25 \\
\hline
\end{tabular}


Myocardial inarction patients with severe hyperglycemia at admission day evidenced a significantly increased mortality both short-term $(15 \%$; vs. $5 \% p<0.001)$ and long-term $(\mathrm{HR}=2.19,95 \%$ CI: $1.66-2.89$; $p<0.001$ ) (Table 4 and Figure 3). ROC analysis for blood glucose concentration was performed for patients suffering from AMI (AUC 0.70, 95\% CI: 0.67-0.72). Myocardial infarction patients with severe hyperglycemia were older (73 (65-79) vs. 68 (57-77) years; $p<0.001)$, more obese (BMI $29 \pm 5$ vs. $28 \pm 4 ; p<0.001$ ) and clinically sicker (APACHE2 score $21 \pm 9$ vs. $16 \pm 8 ; p<0.001$; SAPS2 score $41 \pm 18$ vs. $32 \pm 16 ; p<0.001)$. Blood lactate concentration ( $3.7 \pm 6.1$ vs. $1.8 \pm 1.9 \mathrm{mmol} / \mathrm{L} ; p<0.001)$, heart rate $(101 \pm 22$ vs. $92 \pm 20$ bpm; $p<0.001)$ and white blood cell count $(13.2 \pm 4.9$ vs. $11.2 \pm 5.2 \mathrm{G} / \mathrm{L} ; p<0.001)$ and markers of multi-organ failure were significantly higher in patients with severe hyperglycemia as shown in Table 6. Of note, patients suffering from severe hyperglycemia were more likely to have pre-diagnosed type 2 diabetes $(29 \%$ vs. $10 \% ; p<0.001)$.

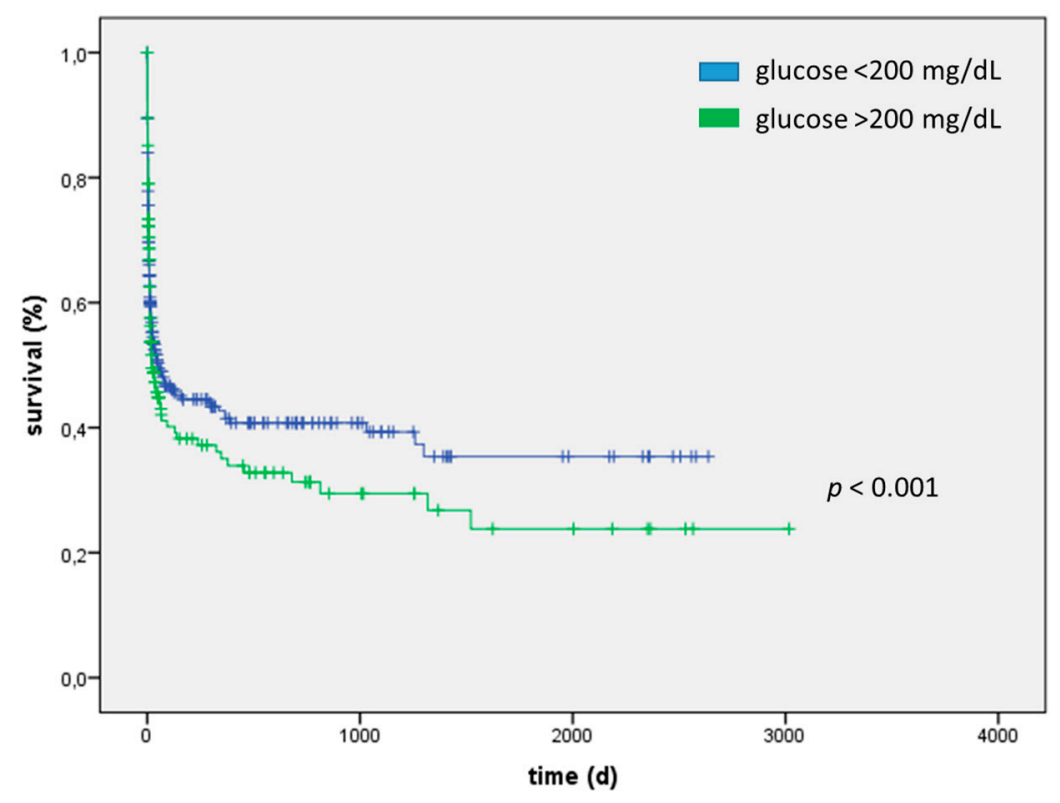

Figure 3. Myocardial infarction patients with severe hyperglycemia at admission day evidenced a significantly increased mortality in the long-term (HR 2.19, 95\% CI: 1.66-2.89; $p<0.001$ ).

Table 6. In patients suffering from AMI and severe hyperglycemia ( $>200 \mathrm{mg} / \mathrm{dL}$ ) were sicker (SAPS2 score $41 \pm 16$ vs. $32 \pm 16 ; p<0.001$ ) and older (73 (65-79) vs. 68 (57-77) years; $p<0.001)$.

\begin{tabular}{cccc}
\hline Parameter & $<\mathbf{2 0 0} \mathbf{~ m g / d L}$ & $>\mathbf{2 0 0} \mathbf{~ m g / d L}$ & $p$-Value \\
\hline age & $68(57-77)$ & $73(65-79)$ & $<0.001$ \\
male & $59 \%$ & $65 \%$ & 0.03 \\
lactate $(\mathrm{mmol} / \mathrm{L})$ & $1.82 \pm 1.94$ & $3.65 \pm 6.05$ & $<0.001$ \\
glucose $(\mathrm{mg} / \mathrm{dL})$ & $139 \pm 30$ & $272 \pm 68$ & $<0.001$ \\
leucocytes $(\mathrm{G} / \mathrm{L})$ & $11.09 \pm 5.23$ & $13.22 \pm 4.92$ & $<0.001$ \\
$($ lowest $) \mathrm{pO}(\mathrm{kPa})$ & $5.53 \pm 1.71$ & $5.12 \pm 1.54$ & 0.02 \\
pCO2 $(\mathrm{kPa})$ & $5.54 \pm 1.16$ & $5.97 \pm 1.76$ & $<0.001$ \\
heart rate $(\mathrm{bpm})$ & $92 \pm 20$ & $101 \pm 22$ & $<0.001$ \\
sodium $(\mathrm{mmol} / \mathrm{L})$ & $139.61 \pm 3.65$ & $140.04 \pm 5.61$ & 0.16 \\
potassium $(\mathrm{mmol} / \mathrm{L})$ & $4.11 \pm 0.51$ & $4.17 \pm 0.61$ & 0.12 \\
type 2 diabetes & $10 \%$ & $29 \%$ & $<0.001$ \\
Creatinine $(\mu \mathrm{mol} / \mathrm{L})$ & $88(75-114)$ & $107(86-155)$ & $<0.001$ \\
ALAT $\left(\mu \mathrm{mol} /\left(\mathrm{l}^{*} \mathrm{~s}\right)\right)$ & $0.7(0.4-1.3)$ & $1.0(0.58-1.6)$ & $<0.001$ \\
ASAT $\left(\mu \mathrm{mol} /\left(\mathrm{l}^{*} \mathrm{~s}\right)\right)$ & $2.0(0.7-4.9)$ & $2.9(1.1-6.2)$ & $<0.001$ \\
APACHE score & $16 \pm 8$ & $21 \pm 8$ & $<0.001$ \\
SAPS2 score & $32 \pm 16$ & $41 \pm 18$ & $<0.001$ \\
BMI $\left(\mathrm{kg} / \mathrm{m}^{2}\right)$ & $28 \pm 4$ & $29 \pm 5$ & 0.001 \\
\hline
\end{tabular}


A medical history of type 2 diabetes $(n=337 ; 13 \%)$ was not associated with increased mortality: Neither intra-ICU ( $15 \%$ vs. $15 \% ; p=0.93)$ nor long term (HR $=1.140,95 \%$ CI: $0.91-1.44 ; p=0.26)$ in the overall cohort, nor in any of the sub-cohorts of AMI patients (HR $=0.82,95 \%$ CI: $0.49-1.38 ; p=0.53$ ) and septic patients ( $\mathrm{HR}=1.29,95 \% \mathrm{CI}$ : 0.79-2.09; $p=0.32$ ), although diabetic patients had higher blood glucose concentrations ( $213 \pm 76$ vs. $175 \pm 70 \mathrm{mg} / \mathrm{dL} ; p<0.001)$, were older (72 (65-78) vs. 68 (57-77) years; $p<0.001$ ), more obese (BMI $29 \pm 4$ vs. $28 \pm 5 ; p<0.001$ ) and clinically sicker (APACHE2 score $22 \pm 10$ vs. $20 \pm 10 ; p=0.02$; SAPS2 score $43 \pm 21$ vs. $40 \pm 20 ; p=0.06$ ) (Table 7).

Table 7. In the overall cohort, patients with a medical history of diabetes (12\%) were sicker in trend (SAPS2 score $43 \pm 21$ vs. $40 \pm 20 ; p=0.06$ ) and older (72 (65-78) vs. 68 (57-76) years; $p<0.001$ ).

\begin{tabular}{cccc}
\hline Parameter & No T2DM & T2DM & $p$-Value \\
\hline age & $68(57-76)$ & $72(65-78)$ & $<0.001$ \\
male & $61 \%$ & $61 \%$ & 0.9 \\
lactate $(\mathrm{mmol} / \mathrm{L})$ & $2.59 \pm 3.17$ & $3.27 \pm 6.88$ & 0.10 \\
glucose $(\mathrm{mg} / \mathrm{dL})$ & $175 \pm 70$ & $213 \pm 76$ & $<0.001$ \\
leucocytes $(\mathrm{G} / \mathrm{L})$ & $12.43 \pm 8.44$ & $12.43 \pm 6.46$ & 0.99 \\
$($ lowest $)$ pO2 $(\mathrm{kPa})$ & $5.53 \pm 1.68$ & $5.46 \pm 1.36$ & 0.64 \\
pCO2 $(\mathrm{kPa})$ & $6.02 \pm 1.74$ & $6.27 \pm 2.38$ & 0.06 \\
heart rate $(\mathrm{bpm})$ & $97 \pm 23$ & $99 \pm 24$ & 0.23 \\
sodium $(\mathrm{mmol} / \mathrm{L})$ & $140.01 \pm 4.55$ & $14.10 \pm 5.13$ & 0.80 \\
potassium $(\mathrm{mmol} / \mathrm{L})$ & $4.13 \pm 0.54$ & $4.14 \pm 0.54$ & 0.65 \\
BMI & $28 \pm 5$ & $29 \pm 4$ & $<0.001$ \\
creatinine $(\mu \mathrm{mol} / \mathrm{L})$ & $93(77-146)$ & $108(86-174)$ & $<0.001$ \\
ALAT $\left(\mu \mathrm{mol} /\left(\mathrm{l}^{*} \mathrm{~s}\right)\right)$ & $0.7(0.4-1.3)$ & $0.7(0.4-1.2)$ & 0.70 \\
ASAT $\left(\mu \mathrm{mol} /\left(\mathrm{l}^{*} \mathrm{~s}\right)\right)$ & $1.7(0.7-4.2)$ & $1.4(0.7-4.2)$ & 0.85 \\
APACHE score & $20 \pm 10$ & $22 \pm 10$ & 0.02 \\
SAPS2 score & $40 \pm 20$ & $43 \pm 21$ & 0.06 \\
intra-ICU survival & $15 \%$ & $15 \%$ & 0.93 \\
\hline
\end{tabular}

Of note, those patients with severe hyperglycemia-indicating at least an increased risk for diabetesand/or a known medical history of type 2 diabetes taken together, evidenced significantly increased short-term $(22 \%$ vs. $13 \% ; p<0.001)$ and long-term mortality (HR $=1.76,95 \%$ CI: $1.47-2.11 ; p<0.001)$ in the overall cohort, as well as in the AMI sub-group (intra-ICU $13 \%$ vs. $5 \% ; p<0.001$ ) long-term $\mathrm{HR}=2.13,95 \%$ CI: $1.61-2.80 ; p<0.001$ ), but not in septic patients (intra-ICU $38 \%$ vs. $41 \% ; p=0.53$; long term HR $=1.24,95 \%$ CI: $0.98-1.57 ; p=0.08$ ).

We further investigated the role of hypoglycemia on the day of admission. In AMI patients $1.2 \%$ and in septic patients $5.4 \%$ suffered from hypoglycemia on admission day. We investigated associations of hypoglycemia, defined as glucose concentration below $50 \mathrm{mg} / \mathrm{dL}$, with mortality. In patients suffering from sepsis hypoglycemia was associated with both long-term $(\mathrm{HR}=2.39$, $95 \%$ CI: $1.51-3.77 ; p<0.001)$ and intra-ICU (68\% vs. $38 \% ; p=0.002)$. In AMI patients hypoglycemia was associated with adverse long-term outcome (HR $=3.12,95 \% \mathrm{CI}: 1.38-7.03 ; p=0.006)$ and with intra-ICU mortality at least in trend $(19 \%$ vs. $8 \% ; p=0.12)$. To exclude an effect of hypoglycemia on the associations between severe hyperglycemia and outcome we excluded patients suffering from hypoglycemia: In septic patients long term mortality (HR $=1.15,95 \% \mathrm{CI}: 0.90-1.48 ; p=0.27)$ and short-term mortality ( $39 \%$ vs. $38 \%$; $p=0.77$ ) were not associated with severe hyperglycemia whereas in patients suffering from AMI severe hyperglycemia was associated with both short-term ( $14 \% \mathrm{vs.} 5 \%$; $p<0.001)$ and long-term mortality ( $\mathrm{HR}=2.19,95 \% \mathrm{CI}: 1.65-2.90 ; p<0.001)$.

\section{Discussion}

Severe hyperglycemia (blood glucose concentration $>200 \mathrm{mg} / \mathrm{dL}$ ) was associated with adverse outcome in the overall cohort and in patients suffering from myocardial infarction, but not in septic 
patients. We therefore think that hyperglycemia should be considered and handled differently in those patient collectives.

It has been proven recently that even a single peak of hyperglycemia can exaggerate oxidative stress, induce cell apoptosis as well as endothelial dysfunction and stimulate coagulation and platelet aggregation [19-23]. We therefore decided to report and investigate effects of the maximum blood glucose concentration on the day of admission to ICU.

Hyperglycemia is well known to be associated with adverse outcomes as well as reduced left ventricular (LV) function in AMI patients [24,25]. It is not clear until now, to what extent these associations are causal and in which way hyperglycemia itself contributes to adverse outcome. Furthermore, hyperglycemia is known to be associated with ischemia-reperfusion injury, increased infarct size in an animal model and tight glycemic control was reported to increase regenerative potential of infarcted myocardium [26-28]. In our study, AMI patients exhibiting severe hyperglycemia had significantly elevated SAPS2 and APACHE scores compared to those without severe hyperglycemia (APACHE2 score $21 \pm 9$ vs. $16 \pm 8 ; p<0.001$; SAPS2 score $41 \pm 18$ vs. $32 \pm 16$; $p<0.001)$ indicating sicker patients in which tissue perfusion is impaired. This finding could be interpreted as evidence for the hypothesis that glucose concentration primarily mirrors illness severity. An investigation of a possible causative relationship between hyperglycemia and adverse outcome is beyond the scope of this study: further, prospective studies and experimental efforts are needed.

In septic patients, maximum glucose concentration on the day of admission was only in trend associated with mortality. Even severe hyperglycemia was not associated with adverse outcome in those patients. In accordance, patients suffering from sepsis and severe hyperglycemia were of similar age compared to septic patients with a blood glucose concentration $<200 \mathrm{mg} / \mathrm{dL}$, and did not evidence higher blood lactate concentrations, increased laboratory markers of multi-organ failure and SAPS2. We think this further supports the notion that hyperglycemia in sepsis, i.e., stress hyperglycemia, should not be considered harmful, as stated before by Tiruvoipati et al. [9]. In this condition, hyperglycemia should primarily be seen as an adaptive mechanism to hypo-perfusion to ensure sufficient glucose supply for peripheral cells by facilitating glucose uptake-a passive mechanism-by increasing blood glucose concentration [10]. Lesur et al. postulated that the stress response of septic patients is different to non-septic ICU patients' levels [29]. In addition, this would be in accordance to prospective studies, e.g., NICE-SUGAR, which could even show an adverse outcome for tight glucose control in septic patients [11].

For blood glucose concentration a U-shaped relationship with outcome was shown in critically ill in several previous studies [30-32]. In our cohort hypoglycemia was associated with adverse outcome for both septic and AMI patients. Still, after exclusion of patients suffering from hypoglycemia the associations we reported in this study between severe hyperglycemia and sepsis or AMI, remained unaltered.

In our study, cohort a medical history of type 2 diabetes was not associated with increased mortality neither intra-ICU nor long both in AMI and septic patients. This goes in line with the findings of Wang and co-workers who could show that although diabetes leads to contractile and metabolic abnormalities during normoxia, there is no association between diabetes and increased susceptibility to injury due to ischemia [33]. On the other hand, whereas in short term optimal intensive care treatment might outplay possible detrimental effects of diabetes, in the long-term we would expect adverse outcome in patients suffering from diabetes mellitus. Only $13 \%$ of our cohort, representing a typical cohort of medical ICU-patients, was pre-diagnosed with diabetes. We therefore speculate that the neutral effect of pre-diagnosed diabetes mellitus in the long-term might be due to under-diagnosis of type 2 diabetes in our cohort, as prevalence in patients aged 65 and older is known to be as high as $25 \%$ (and rising) [34]. Due to the retrospective design of our study, we could not further elucidate this hypothesis as neither oral glucose tolerance test results nor Hba1c levels were available for analysis. This speculation is in contrast to findings of Ishihara et al. who could show-for their cohort of AMI patients-that patients with stress hyperglycemia did not show increased prevalence of diabetes at 
the time of presentation by means of oral glucose tolerance test (OGTT) [35]. Of note, OGTT might underdiagnose diabetes compared to $\mathrm{Hba} 1 \mathrm{c}$ and stress hyperglycemia might still be associated with higher risk for developing diabetes [36,37].

As others reported that patients evidencing stress hyperglycemia are known to be at higher risk for impaired fasting glucose and developing diabetes, we aimed to find out if patients with a known medical history of diabetes and/or severe hyperglycemia on the admission day had adverse outcome [38,39]: This was true for the overall cohort and AMI patients (intra-ICU mortality $13 \% \mathrm{vs.} 5 \%$; $p<0.001$; long-term mortality HR $=2.13,95 \%$ CI: $1.61-2.80 ; p<0.001$ ) but could not be shown for septic patients (intra-ICU mortality $41 \%$ vs. $38 \% ; p=0.53$; long term mortality HR $=1.24,95 \%$ CI: $0.98-1.57$; $p=0.08$ ). This of course does not proof a relationship of stress hyperglycemia and diabetes but we strongly believe that this further under-strikes a primarily beneficial role of hyperglycemia in septic patients. On the other hand, in patients suffering from AMI, severe hyperglycemia might mirror both the severity of the acute event, as well as the patients' comorbidities, such as diabetes, and therefore identify patients at high risk for death.

\section{Methods}

From 2006 to 2009, 2528 patients admitted to the Medical ICU at the Jena University Hospital because of either myocardial infarction $(n=1979)$ or sepsis $(n=549)$ were investigated retrospectively. Diagnosis and treatment of AMI was done according to ESC guidelines [40,41]. All patients diagnosed with AMI were admitted to ICU with exception of patients provided palliative care. Sepsis was defined as systemic inflammatory response syndrome accompanied by either microbiologically confirmed or clinically suspected infection $[42,43]$.

Follow-up of patients was performed between May 2013 and November 2013. The primary endpoint of the study was death of any cause. Data on mortality were collected upon review of electronic in-hospital medical records or phone interviews and could be collected in $97.5 \%$ of patients. The study was approved by the local ethics committee of the Medical Faculty of the Friedrich Schiller University of Jena.

\subsection{Laboratory Analysis}

Blood samples were taken according to standard care. Laboratory parameters were obtained from the Department of Clinical Chemistry and Laboratory Medicine at the Jena University Hospital. Some laboratory values were measured repeatedly on the day of admission and we report the maximum value unless stated differently. Blood glucose concentration was measured in venous blood.

\subsection{Calculation of SAPS2 and APACHE Score}

Initial Simplified Acute Physiology Score II (SAPS2) and Acute Physiology And Chronic Health Evaluation (APACHE) scores were calculated by the treating physician within $24 \mathrm{~h}$ after admission as reported before [44,45].

\subsection{Statistical Analysis}

Statistical analysis was performed using SPSS (IBM Corp. Released 2013. IBM SPSS Statistics for Windows, Version 22.0. Armonk, NY, USA: IBM Corp.). Normally distributed data is given in mean \pm standard deviation and compared by student's $t$-test. Non-normally distributed data is given as median \pm inter-quartile-range and compared by Mann-Whitney- $U$-Test. Chi-square test was applied to calculate differences between groups. Cox regression analysis was used to compare and Kaplan-Meier curve was used to depict survival data. ROC analysis was performed and area under the curve (AUC) was calculated. 


\section{Conclusions}

In conclusion, we speculate about a Janus-faced role of severe hyperglycemia in critically ill patients: Whereas severe hyperglycemia in AMI patients might mirror and identify a sicker patient collective probably suffering from pre-diabetes or even undiagnosed diabetes, with its' known adverse consequences on outcome, hyperglycemia in sepsis should primarily be seen as adaptive mechanism to impaired hemodynamics. Our study adds a comprehensive comparison of the association of severe hyperglycemia and mortality in AMI versus septic patients.

In our opinion, in the short-term, hyperglycemia should still be treated only liberally in both patients suffering from AMI as well as from sepsis, and glucose control should primarily focus on avoidance of fluid shifts due to changes in plasma osmolality. However, AMI patients with hyperglycemic derailment during an ICU-stay might be at higher risk of diabetes and consequent death. We therefore would like to suggest that these patients should be closely followed-up and extensively screened for diabetes and its complications to ensure optimal long-term outcome for all our patients.

\section{Limitations}

Our study is of single-center and retrospective nature. Regarding diagnosis of diabetes, we have neither Hba1c nor OGTT values but data from medical history. Moreover, there were no data available on either the pathogenesis of sepsis / AMI in our patients collective nor the cause of death. Patients were treated according to the treating physician's decisions following international guidelines, but we have no data about specific antibiotic regime, parenteral/enteral nutrition and other medical interventions. Especially, we have no specific data about blood glucose management as this too was handled according to the treating physician. As there were investigated three times as many patients suffering from AMI compared to sepsis, the sepsis cohort could be underpowered for investigation of long-term mortality, but still clinical and laboratory markers differ significantly between AMI and septic patients with or without severe hyperglycemia.

Despite these limitations, we believe that our study is of value to under-strike the different implications of hyperglycemia in ICU patients admitted for either sepsis or AMI.

Acknowledgments: Funding for publishing in open access was provided by Department of Cardiology, Paracelsus Medical University of Salzburg.

Author Contributions: Bernhard Wernly, Christian Jung and Michael Lichtenauer analyzed the data and wrote the first draft of the paper. Marcus Franz and Maryna Masyuk and Johanna Muessig and Bjoern Kabisch contributed to statistical analyisis and improved the manuscript. Uta C. Hoppe, Christian Jung and Malte Kelm contributed analysis tools and materials and gave guidance.

Conflicts of Interest: The authors declare no conflict of interest.

\section{References}

1. Capes, S.E.; Hunt, D.; Malmberg, K.; Gerstein, H.C. Stress hyperglycaemia and increased risk of death after myocardial infarction in patients with and without diabetes: A systematic overview. Lancet 2000, 355, 773-778. [CrossRef]

2. Van den Berghe, G. Molecular biology: A timely tool for further unraveling the "diabetes of stress". Crit. Care Med. 2001, 29, 910-911. [CrossRef] [PubMed]

3. Laird, A.M.; Miller, P.R.; Kilgo, P.D.; Meredith, J.W.; Chang, M.C. Relationship of early hyperglycemia to mortality in trauma patients. J. Trauma 2004, 56, 1058-1062. [CrossRef] [PubMed]

4. Dungan, K.M.; Braithwaite, S.S.; Preiser, J.C. Stress hyperglycaemia. Lancet 2009, 373, 1798-1807. [CrossRef]

5. Hoebers, L.P.; Damman, P.; Claessen, B.E.; Vis, M.M.; Baan, J., Jr.; van Straalen, J.P.; Fischer, J.; Koch, K.T.; Tijssen, J.G.; de Winter, R.J.; et al. Predictive value of plasma glucose level on admission for short and long term mortality in patients with ST-elevation myocardial infarction treated with primary percutaneous coronary intervention. Am. J. Cardiol. 2012, 109, 53-59. [CrossRef] [PubMed] 
6. Dugan, L.L.; You, Y.H.; Ali, S.S.; Diamond-Stanic, M.; Miyamoto, S.; de Cleves, A.E.; Andreyev, A.; Quach, T.; Ly, S.; Shekhtman, G.; et al. AMPK dysregulation promotes diabetes-related reduction of superoxide and mitochondrial function. J. Clin. Investig. 2013, 123, 4888-4899. [CrossRef] [PubMed]

7. Brownlee, M. Biochemistry and molecular cell biology of diabetic complications. Nature 2001, 414, 813-820. [CrossRef] [PubMed]

8. Van Vught, L.A.; Wiewel, M.A.; Klein-Klouwenberg, P.M.; Hoogendijk, A.J.; Scicluna, B.P.; Ong, D.S.; Cremer, O.L.; Horn, J.; Bonten, M.M.; Schultz, M.J.; et al. Admission hyperglycemia in critically ill sepsis patients: Association with outcome and host response. Crit. Care Med. 2016, 44, 1338-1346. [CrossRef] [PubMed]

9. Tiruvoipati, R.; Chiezey, B.; Lewis, D.; Ong, K.; Villanueva, E.; Haji, K.; Botha, J. Stress hyperglycemia may not be harmful in critically ill patients with sepsis. J. Crit. Care 2012, 27, 153-158. [CrossRef] [PubMed]

10. Losser, M.R.; Damoisel, C.; Payen, D. Bench-to-bedside review: Glucose and stress conditions in the intensive care unit. Crit. Care 2010, 14. [CrossRef] [PubMed]

11. Investigators, N.-S.S.; Finfer, S.; Chittock, D.R.; Su, S.Y.; Blair, D.; Foster, D.; Dhingra, V.; Bellomo, R.; Cook, D.; Dodek, P.; et al. Intensive versus conventional glucose control in critically ill patients. N. Engl. J. Med. 2009, 360, 1283-1297.

12. Preiser, J.C.; Devos, P.; Ruiz-Santana, S.; Melot, C.; Annane, D.; Groeneveld, J.; Iapichino, G.; Leverve, X.; Nitenberg, G.; Singer, P.; et al. A prospective randomised multi-centre controlled trial on tight glucose control by intensive insulin therapy in adult intensive care units: The Glucontrol study. Intensive Care Med. 2009, 35, 1738-1748. [CrossRef] [PubMed]

13. De La Rosa, G.D.C.; Donado, J.H.; Restrepo, A.H.; Quintero, A.M.; Gonzalez, L.G.; Saldarriaga, N.E.; Bedoya, M.; Toro, J.M.; Velasquez, J.B.; Valencia, J.C.; et al. Strict glycaemic control in patients hospitalised in a mixed medical and surgical intensive care unit: A randomised clinical trial. Crit. Care 2008, 12. [CrossRef] [PubMed]

14. Marik, P.E.; Bellomo, R. Stress hyperglycemia: An essential survival response! Crit. Care 2013, 17. [CrossRef] [PubMed]

15. Koh, G.C.; Peacock, S.J.; van der Poll, T.; Wiersinga, W.J. The impact of diabetes on the pathogenesis of sepsis. Eur. J. Clin. Microbiol. Infect. Dis. 2012, 31, 379-388. [CrossRef] [PubMed]

16. Bannier, K.; Lichtenauer, M.; Franz, M.; Fritzenwanger, M.; Kabisch, B.; Figulla, H.R.; Pfeifer, R.; Jung, C. Impact of diabetes mellitus and its complications: Survival and quality-of-life in critically ill patients. J. Diabetes Complicat. 2015, 29, 1130-1135. [CrossRef] [PubMed]

17. Jung, C.; Rafnsson, A.; Shemyakin, A.; Bohm, F.; Pernow, J. Different subpopulations of endothelial progenitor cells and circulating apoptotic progenitor cells in patients with vascular disease and diabetes. Int. J. Cardiol. 2010, 143, 368-372. [CrossRef] [PubMed]

18. Esper, A.M.; Moss, M.; Martin, G.S. The effect of diabetes mellitus on organ dysfunction with sepsis: An epidemiological study. Crit. Care 2009, 13. [CrossRef] [PubMed]

19. Esposito, K.; Nappo, F.; Marfella, R.; Giugliano, G.; Giugliano, F.; Ciotola, M.; Quagliaro, L.; Ceriello, A.; Giugliano, D. Inflammatory cytokine concentrations are acutely increased by hyperglycemia in humans: Role of oxidative stress. Circulation 2002, 106, 2067-2072. [CrossRef] [PubMed]

20. Risso, A.; Mercuri, F.; Quagliaro, L.; Damante, G.; Ceriello, A. Intermittent high glucose enhances apoptosis in human umbilical vein endothelial cells in culture. Am. J. Physiol. Endocrinol. Metab. 2001, 281, E924-E930. [PubMed]

21. Williams, S.B.; Goldfine, A.B.; Timimi, F.K.; Ting, H.H.; Roddy, M.A.; Simonson, D.C.; Creager, M.A. Acute hyperglycemia attenuates endothelium-dependent vasodilation in humans in vivo. Circulation 1998, 97, 1695-1701. [CrossRef] [PubMed]

22. Stegenga, M.E.; van der Crabben, S.N.; Levi, M.; de Vos, A.F.; Tanck, M.W.; Sauerwein, H.P.; van der Poll, T. Hyperglycemia stimulates coagulation, whereas hyperinsulinemia impairs fibrinolysis in healthy humans. Diabetes 2006, 55, 1807-1812. [CrossRef] [PubMed]

23. Mapanga, R.F.; Joseph, D.; Symington, B.; Garson, K.L.; Kimar, C.; Kelly-Laubscher, R.; Essop, M.F. Detrimental effects of acute hyperglycaemia on the rat heart. Acta Physiol. 2014, 210, 546-564. [CrossRef] [PubMed]

24. Ishihara, M. Acute hyperglycemia in patients with acute myocardial infarction. Circ. J. 2012, 76, 563-571. [CrossRef] [PubMed] 
25. Stranders, I.; Diamant, M.; van Gelder, R.E.; Spruijt, H.J.; Twisk, J.W.; Heine, R.J.; Visser, F.C. Admission blood glucose level as risk indicator of death after myocardial infarction in patients with and without diabetes mellitus. Arch. Intern. Med. 2004, 164, 982-988. [CrossRef] [PubMed]

26. Takahashi, M.; Chen-Yoshikawa, T.F.; Menju, T.; Ohata, K.; Kondo, T.; Motoyama, H.; Hijiya, K.; Aoyama, A.; Date, H. Inhibition of Toll-like receptor 4 signaling ameliorates lung ischemia-reperfusion injury in acute hyperglycemic conditions. J. Heart Lung Trans. 2016, 35, 815-822. [CrossRef] [PubMed]

27. Marfella, R.; Sasso, F.C.; Cacciapuoti, F.; Portoghese, M.; Rizzo, M.R.; Siniscalchi, M.; Carbonara, O.; Ferraraccio, F.; Torella, M.; Petrella, A.; et al. Tight glycemic control may increase regenerative potential of myocardium during acute infarction. J. Clin. Endocrinol. Metab. 2012, 97, 933-942. [CrossRef] [PubMed]

28. Di Filippo, C.; Marfella, R.; Cuzzocrea, S.; Piegari, E.; Petronella, P.; Giugliano, D.; Rossi, F.; D’Amico, M. Hyperglycemia in streptozotocin-induced diabetic rat increases infarct size associated with low levels of myocardial HO-1 during ischemia/reperfusion. Diabetes 2005, 54, 803-810. [CrossRef] [PubMed]

29. Lesur, O.; Roussy, J.F.; Chagnon, F.; Gallo-Payet, N.; Dumaine, R.; Sarret, P.; Chraibi, A.; Chouinard, L.; Hogue, B. Proven infection-related sepsis induces a differential stress response early after ICU admission. Crit. Care 2010, 14. [CrossRef] [PubMed]

30. Pinto, D.S.; Skolnick, A.H.; Kirtane, A.J.; Murphy, S.A.; Barron, H.V.; Giugliano, R.P.; Cannon, C.P.; Braunwald, E.; Gibson, C.M.; Group, T.S. U-shaped relationship of blood glucose with adverse outcomes among patients with ST-segment elevation myocardial infarction. J. Am. Coll. Cardiol. 2005, 46, 178-80. [CrossRef] [PubMed]

31. Ntaios, G.; Egli, M.; Faouzi, M.; Michel, P. J-shaped association between serum glucose and functional outcome in acute ischemic stroke. Stroke 2010, 41, 2366-2370. [CrossRef] [PubMed]

32. Li, Y.; Bai, Z.; Li, M.; Wang, X.; Pan, J.; Li, X.; Wang, J.; Feng, X. U-shaped relationship between early blood glucose and mortality in critically ill children. BMC Pediatr. 2015, 15. [CrossRef] [PubMed]

33. Wang, P.; Chatham, J.C. Onset of diabetes in Zucker diabetic fatty (ZDF) rats leads to improved recovery of function after ischemia in the isolated perfused heart. Am. J. Physiol. Endocrinol. Metab. 2004, 286, E725-E736. [CrossRef] [PubMed]

34. Wild, S.; Roglic, G.; Green, A.; Sicree, R.; King, H. Global prevalence of diabetes: Estimates for the year 2000 and projections for 2030. Diabetes Care 2004, 27, 1047-1053. [CrossRef] [PubMed]

35. Ishihara, M.; Inoue, I.; Kawagoe, T.; Shimatani, Y.; Kurisu, S.; Hata, T.; Nakama, Y.; Kijima, Y.; Kagawa, E. Is admission hyperglycaemia in non-diabetic patients with acute myocardial infarction a surrogate for previously undiagnosed abnormal glucose tolerance? Eur. Heart J. 2006, 27, 2413-2419. [CrossRef] [PubMed]

36. Hjellestad, I.D.; Astor, M.C.; Nilsen, R.M.; Softeland, E.; Jonung, T. HbA(1)c versus oral glucose tolerance test as a method to diagnose diabetes mellitus in vascular surgery patients. Cardiovasc. Diabetol. $2013,12$. [CrossRef] [PubMed]

37. Sacks, D.B. A1C versus glucose testing: A comparison. Diabetes Care 2011, 34, 518-523. [CrossRef] [PubMed]

38. Vancheri, F.; Curcio, M.; Burgio, A.; Salvaggio, S.; Gruttadauria, G.; Lunetta, M.C.; Dovico, R.; Alletto, M. Impaired glucose metabolism in patients with acute stroke and no previous diagnosis of diabetes mellitus. QJM Int. J. Med. 2005, 98, 871-878. [CrossRef] [PubMed]

39. Greci, L.S.; Kailasam, M.; Malkani, S.; Katz, D.L.; Hulinsky, I.; Ahmadi, R.; Nawaz, H. Utility of HbA(1c) levels for diabetes case finding in hospitalized patients with hyperglycemia. Diabetes Care 2003, 26, 1064-1068. [CrossRef] [PubMed]

40. Roffi, M.; Patrono, C.; Collet, J.P.; Mueller, C.; Valgimigli, M.; Andreotti, F.; Bax, J.J.; Borger, M.A.; Brotons, C.; Chew, D.P.; et al. Management of Acute Coronary Syndromes in Patients Presenting without Persistent STSEotESoC. 2015 ESC Guidelines for the management of acute coronary syndromes in patients presenting without persistent ST-segment elevation: Task Force for the Management of Acute Coronary Syndromes in Patients Presenting without Persistent ST-Segment Elevation of the European Society of Cardiology (ESC). Eur. Heart J. 2016, 37, 267-315. [PubMed]

41. Steg, P.G.; James, S.K.; Atar, D.; Badano, L.P.; Blomstrom-Lundqvist, C.; Borger, M.A.; Di Mario, C.; Dickstein, K.; Ducrocq, G.; Fernandez-Aviles, F.; et al. ESC Guidelines for the management of acute myocardial infarction in patients presenting with ST-segment elevation. Eur. Heart J. 2012, 33, 2569-2619. [CrossRef] [PubMed] 
42. Bone, R.C.; Balk, R.A.; Cerra, F.B.; Dellinger, R.P.; Fein, A.M.; Knaus, W.A.; Schein, R.M.; Sibbald, W.J. Definitions for sepsis and organ failure and guidelines for the use of innovative therapies in sepsis. Chest 1992, 101, 1644-1655. [CrossRef] [PubMed]

43. Soong, J.; Soni, N. Sepsis: Recognition and treatment. Clin. Med. 2012, 12, 276-280. [CrossRef]

44. Le Gall, J.R.; Lemeshow, S.; Saulnier, F. A new simplified acute physiology score (SAPS II) based on a European/North American multicenter study. J. Am. Med. Assoc. 1993, 270, 2957-2963. [CrossRef]

45. Knaus, W.A.; Zimmerman, J.E.; Wagner, D.P.; Draper, E.A.; Lawrence, D.E. APACHE-acute physiology and chronic health evaluation: A physiologically based classification system. Crit. Care Med. 1981, 9, 591-597. [CrossRef] [PubMed]

(C) 2016 by the authors; licensee MDPI, Basel, Switzerland. This article is an open access article distributed under the terms and conditions of the Creative Commons Attribution (CC-BY) license (http://creativecommons.org/licenses/by/4.0/). 